\title{
Cardiac Looping and Formation of the Heart Regions in Japanese Quail Embryo (Coturnix coturnix).
}

\author{
A.S. Saber, K.M. Shoghy, A.M. Erasha and M.M.Nada \\ Department of Anatomy \& Embryology, Faculty of Vet. Med., Sadat City Branch, Menoufiya university, EGYPT \\ E-mail : saberashraf_2@yahoo.com
}

Received January2008;accepted for publication Marsh 2008

\begin{abstract}
In this study the morphological changes of the developing 100 heart tubes and formation of the heart regions in Quail embryos were examined from the first till the fourth day of development. Special dissecting tools were prepared and used for dissecting the embryos, normal histological techniques for the histological study were adopted and the binocular stereomicroscope, inverted microscope and light microscopes were used.
\end{abstract}

The study proved that the cardiac looping of the Quail embryos, like that of the chick embryos, took 3 stages but occurred earlier: the straight heart tube of the quail was formed at about 24-26 hours of the development. The stage of dextral looping took the period between 26 and 40 hours of the development. The Transformation of the C-shaped heart loop into the S-shaped heart loop started at 39-40 hours and finished at 52-55 hours of the development. The process of cardiac looping was accompanied by formation of the heart regions and followed by positional changes and disappearance of the Bulbus cordis.

The results obtained are important for the embryologists using the quail-chick chimera system in the development. Both quail and chick embryos used in this system must be

at the comparable not the same ages of the development to avoid the malformations resulted from using the miss ages.

\section{Key Words}

Cardiac loop, heart formation, Japanese quail

\section{Introduction}

For several decades, the chick embryos considered as the ideal object for embryological studies, but during the past few years the quail embryos at tracted the attention of many of the embryologists because of its special character where it has a short life cycle (16 to 17 days incubation period unlike that of the chick embryos which are 21 days, and ap

proximately 42 days are required from hatching to reach the sexual maturity) and the large number of eggs that obtained per female in one year " up to 300 or more " (Sainsbury, 1992).

The interest taken by the embryologists in the heart development arises mainly from the fact that the heart is the first organ of vertebrate embryos begins to function during embryonic development. Furthermore, it is unique in that it becomes physiologically active before its morphogenesis is completed. (Schoenwolf et al., 1995; Icardo, 1996; Cooke and Issac, 1998; Harvey, 1998; Beddington and Robertson, 1999).

The history of research on the developing heart traced back for more than 300 years (Malpighi, 1672; Haller, 1758; Wolff, 1764; Pander, 1817; His, $1881,1885)$. Haller (1758) seems to be the first one who noted that the embryonic heart passes through a developmental phase where it shows the morphology of a loop. Since then, the term "heart loop" has been used in the embryological literature when characterizing the morphology of the early embryonic hearts.

Studying the embryonic heart development helps the pathologists to answer their questions about the abnormalities of the heart, for example, topographical anomalies of the heart chambers (ventricular inversion) might be explained by the abnormal lateralization of the embryonic heart loop to the left instead of to the right of the body (Lewis and Abbott, 1915, 1916; Van Praagh, 1972).

The aim of this study is to trace the external morphological changes of the heart tube and its different 
regions of the quail embryo and to notice if there are any differences between it and other bird species, especially chick embryos. These data are useful for embryologists interesting recently with the quailchick chimera system (transplantation) applications in the developmental study (Long et al., 2001; Männer et al., 2001; Etchevers et al., 2002; Luttun and Carmeliet, 2003; Dupin and Le Douarin, 2003; Le Douarin, 2004; Creuzet et al.,-2005).

\section{Material and Methods}

Two hundreds Fertilized eggs of the Japanese quail (Coturnix coturnix japonica) were used in this study. The eggs were kept at $10-15^{\circ} \mathrm{C}$ before use (up to one week). Then it were incubated at $60 \%$ relative humidity and $37^{\circ} \mathrm{C}$ until the day of hatching.

Dissection and manipulation of the quail embryos from the first till the fourth day of development was performed under binocular stereo microscope. The heart area was exposed and the external morphological changes of the developing heart were investigated and photographed under stereo and inverted microscopes.

\section{Preparation of tools for dissection:}

The middle part of the glass rod of $5 \mathrm{~mm}$ diameter heated over the flame of a Bunsen burner until it began to melt. Then after the glass bar was removed from the flame and its two ends were quickly pulled apart to form a thread. The glass thread was cut at the middle to form two glass bars, each of them with one sharp end. The sharp end was heated over the Bunsen burner and then further extended with a pair of forceps to form a long thin sharp end enough for dissection. Also we adopted this method with the glass Pasteur pipette and the sharp edge of the anterior end resulted from the melting and the pulling process used in the microscopic dissection.

The terminology which is applied to various parts of the developing quail heart was adapted from Nomina Veterinaria Embryologica (2006). However, the listed abbreviations for our figures were freely used as possible as we can to identify the different components of the developing quail heart.

\section{Results}

\section{(I) Formation of the straight heart tube}

The first morphological manifestation of the straight heart tube in the quail is found at about 24 - 26 hour of the development. The heart tubes of this stage consist only of the Ventriculus primitivus, the primordium of the apical trabeculated region of Ventriculus dexter. This heart tube is connected cranially with the Aorta ventrale and caudally with the Vena omphalomesenterica (Figs. 1).

(2)Transformation of the straight heart tube into the c-shaped heart loop (Dextral-looping)

Subsequent to its first appearance, the straight heart tube shows a rapid elongation along the craniocaudal axis of the embryo leading to the deepening of the left border of the heart which is the first sign of the dextral looping (Figs. 2).

There is not only a slight increase in the craniocaudal length at about 28 hour of the development, but also an increase in the diameter that is especially pronounced at the caudal two thirds of the heart tube. This process appears to be the first morphological sign of a regional differentiation into a less thickened cranial outflow portion or Bulbus cordis and a more thickened caudal portion or Ventriculus primitivus (Fig. 2). At the same age, the Atrium primitivum begins to appear caudal to the Ventriculus primitivus.

The regional differentiation of the heart tube into Bulbus cordis, Ventriculus primitivus and Atrium primitivum becomes more prominent at subsequent steps of dextral-looping. At about 30 hour of the development, a furrow, the Sulcus bulboventricularis, appears at the junction between the Bulbus cordis and Ventriculus primitivus. Another furrow, the Sulcus Atrioventricularis, appears between the dilated Atrium primitivum and the Ventriculus primitivus (Figs. 3).

The positional and morphological changes of the Ventriculus primitivus can be followed using the original ventral midline of the straight heart tubes as a landmark. Thereby, it becomes apparent that the Ventriculus primitivus bends in fact toward its original ventral side. The bending portion of the heart tube simultaneously flaps to the right like a door whose imaginary hinge points are being fixed to the craniocaudal axis of the embryo (Figs. 4,5 ). Thus, the original ventral and dorsal sides of the straight heart tube become the convex right and concave left sides respectively. The original left and right sides of the straight heart tube become the ventral and dorsal sides respectively. Rightward flapping of the Ventriculus primitivus is usually completed at 39 hour of the development. However it may extend to 48 hour of the development.

The end of the rightward flapping process is accomnanied hy the firct mornholnaical manifectation of 
the Sinus venosus which is located caudal to the Atrium primitivum and is separated from it by the Sulcus sinoatrialis (Fig. 4).

Because of the rightward flapping of the Ventriculus primitivus and the dilatation of the Atrium primitivum, a considerable elongation occurs to the junction between the two previous regions at about 38 hour of the development called Canalis atrioventricularis which becomes apparent at the subsequent steps of the development (Fig. 4).

The heart loop of this stage, therefore, is composed of four morphologically distinguishable components. These are in caudocranial sequence: (1) the Atrium primitivum; (2) the Ventriculus primitivus bend that is subdivided by the original "left" lateral furrow into a proximal and a distal portion; (3) the Bulbus cordis; and (4) the Sinus venosus.

Dextral-looping or formation of the c-shaped heart loop is commonly said to be finished with completion of the rightward flapping/lateralization of the Ventriculus primitivus. However, it becomes apparent that the Ventriculus primitivus bend is not the only region of the heart tube that becomes displaced to the right of the body. Soon after completion of the rightward flapping of the ventricular bend, the Bulbus cordis also becomes displaced to the right. This process differs from the rightward displacement of the Ventriculus primitivus bend.

The Bulbus cordis does not bend but remains an almost straight tube. During rightward flapping of the Ventriculus primitivus bend, the longitudinal axis of the Bulbus cordis still runs parallel to the craniocaudal axis of the embryo. Flapping of the Ventriculus primitivus bend does not lead to lateralization of the Bulbus cordis but merely to a torsion between its caudal and cranial ends (Figs. 4, 5).

The displacement of the Bulbus cordis to the right is best described as rightward "kinking". Thereby, the longitudinal axis of the Bulbus cordis shifts from its original vertical direction to an almost horizontal direction.

\section{(3)Transformation of the c-shaped heart loop} into the s-shaped heart loop:

The period following dextral-looping is characterized mainly by two morphogenetic events: (1) shortening of the distance between the caudal wall of the Bulbus cordis and the cranial wall of the Atrium primitivum which begins at 39 - $40 \mathrm{hr}$ of the development (Fig. 5). (2) the shift of the Ventriculus primitivus bend from its original position cranial to the Atrium primi- tivum towards its definitive position caudal to the atria by carrying of the Ventriculus primitivus over the dextral side of the Atrium primitivum (Figs. 6, 7, 8). These events commence at $40-48 \mathrm{hr}$ of the development and finish at $52-55$ hours of the development.

These morphological changes are accompanied by the enlargement of lateral expansions of the atrial region (Fig. 8); by the movement of the Sinus venosus from its original position caudal to the atria toward its definitive position dorsal to the atria (Fig. 9); by the disappearance of the former Left lateral furrow; and by general growth of the heart tube.

\section{(4) Positional changes of the Bulbus cordis}

The period following the establishment of the sshaped heart loop is characterized mainly by two morphogenetic events: (1) the morphological appearance of the tubular anlage of the future great arteries (Truncus arteriosus) at the arterial pole of the heart at $50-52$ hours of the development (Fig. 8 ) and (2) the shift of the proximal two thirds of the Bulbus cordis from cranial to the atria toward its definitive position ventral to the Atrium dextrum (Fig. 10).

\section{(5) Disappearance of the Bulbus cordis}

During the period between 60 - 75 hours of the development, the Sulcus bulboventricularis gradually disappears as the proximal part of the Bulbus cordis is incorporated into the Ventriculus primitivus, while the distal part of the Bulbus cordis becomes the proximal part of the Truncus arteriosus. The part of the ventricle that narrows abruptly to give rise to the Truncus arteriosus is termed the ventricular cone or Conus arteriosus (Figs. 10, 11, 12).

\section{(6) External division of the heart chambers}

At about 30 hours of the development, the Ventriculus primitivus begins to be demarcated from the Bulbus cordis by the Sulcus bulboventricularis and from the atrium by the Sulcus atrioventricularis (Fig. 3). These grooves become clearly apparent at about 38 - 40 hours of the development (Fig. 4). At about 48 hour of the development, the ventricle loses its former U-shaped configuration and becomes quite saccular (Fig. 6).

The first external indication of the internal division of the Ventriculus primitivus into right and left ventricular chambers appears at about 60 63 hours of the development, when a slight groove, originating on its inner curvature, extends caudal and to the right on its ventral sur- 
face called Sulcus interventricularis (Fig. 10). As this Sulcus interventricularis becomes deeper (Figs. 12,13), it divides the ventricle unequally, so that, the left side is larger than the right one. During the fourth day of the development, the right side of the ventricle starts to expand (Figs. 15c; 16b), and by later development of the heart, the Sulcus interventricularis becomes less apparent as the muscular wall of the heart grows thicker (Figs. 17b; 18).

The Atrium primitivum incorporates into the heart at 28-30 hours of the development (Figs. $2,3)$, and begins to expand laterally at 38-40 hours of the development (Fig.4,5). Its expansion, which is marked on the left side, deepens the Sulcus atrioventricularis (Fig. 6).

As the atrium grows, it tends to expand on either side of the depression made in it by the pressure of the Truncus arteriosus (Figs. 11, 12). A longitudinal groove appears on the cranio-ventral surface of the atrium, marking the location of the Septum interatriale (Fig. 11), so that, the Bulbus cordis and the Truncus arteriosus gradually sink down between the two enlarged atria. By later development of the heart the Bulbus cordis disappears, as mentioned before, leaving the Truncus arteriosus alone in the sulcus (Figs. 15,16).

All these previous events are accompanied by general growth of the heart and by gradual expansion of the ventricular bend and primitive atria, which eventually lead to: firstly, loss of the original tubular character of the heart by gradual disappearance of the original lateral furrow (Figs. 13, 14, 16b) and shortening of the Canalis atrioventricularis (Fig. $17 a)$; secondly, formation of the four-chambered heart where the atria are directed dorsally forming the base of the heart and the ventricles are directed ventrally forming the apex which is formed by the Ventriculus sinister (Figs. 17a; 17b); and finally, the gradual increase of the cardiac musculature to reach the adult quail heart shape.

\section{Discussion}

\section{Mechanism of the cardiac looping}

The results of the present study agreed with that of Männer (2000) on the chick embryo heart who claimed that, the cardiac looping is not only dextrallooping (c-shaped heart loop) but also is followed by the transformation of the c-shaped heart loop into the s-shaped heart loop, and the late positional changes of the Bulbus cordis.
Dextral-looping was originally believed to result from the combined action intrinsic and extrinsic to the heart tube. Patten (1922) claimed that the heart tube was forced to bend because its growth in craniocaudal length exceeded that of the concomitant increase in distance between the fixed arterial and venous ends of the heart. This bending must be laterally because of the further restrictions which impart the growth of the heart dorsally by the body of the embryo and ventrally by the yolk.

Another concept favoring the combined action of extrinsic and intrinsic forces tried to explain the lateralization of the ventricular bend by asymmetric routing of the blood flow to the venous end of the heart (Roux, 1895; Spitzer, 1851). On the contrary, Manning and McLachlan (1990) proved that the cardiac looping is a process primarily intrinsic to the heart and Manasek and Monroe (1972) showed that the dextrallooping was not prevented by arresting the circulation of early chick embryos.

The present study supported the hypothesis of the two latter authors that the cardiac looping is a process primarily intrinsic to the heart not an extrinsic one.

The existence of a relationship between the formation of the embryonic head flexures and the cardiac looping has been confirmed experimentally. Stiffening the embryonic head and neck regions with a straight hair prevented the formation of the cranial and cervical flexures. It also concomitantly suppressed the caudal shift of the ventricular bend and the shortening of the distance between the caudal wall of the Bulbus cords and the cranial wall of the Atrium primitivum (Männer et al., 1993). His (1881) and Patten (1922) suggested that the latter two events resulted from the compression of the heart loop by the bending of head and neck regions. On contrast, Waddington, (1937); Flynn et al., (1991) supported the view, that the cervical region is flexed by the caudal shift of the ventricular bend. Recent experiments disproved this idea by showing that the heart-deprived chick embryos will form the cervical flexures, indicating that the cervical flexure formation is not caused by the caudal shift of the ventricular bend (Männer et al., 1995).

It is, therefore, conceivable that the bending of head and neck regions of the embryo to the heart loop might indeed be responsible for the positional changes characterizing the stage of transformation of the c-shaped heart loop into s-shaped heart loop, a view which we also support. 
The mechanisms involved in the positional changes of the Bulbus cordis is still mistry. It might be interesting that the morphological appearance and elongation of the Truncus arteriosus coincides with the ventral shift of the Bulbus cordis, suggesting that the growth of the Truncus arteriosus is related to the late positional changes of the heart loop.

\section{Time of the cardiac loop development:}

Romanoff, (1960) and Patten (1964) found that the straight heart tube of the chick embryo is formed at about 32-33 hr of the development. Our result on the quail embryo heart claimed that the straight heart tube is formed at about $24-26 \mathrm{hr}$ of the development.

Romanoff, (1960); Patten (1964); Patten and Carlson (1974); Männer (2000) mentioned that the stage of dextral looping lasts 33-49 hr of the development, while in the quail embryo heart it takes the period between 26 and 40 hours.

Männer (2000) concluded that transformation of the c-shaped heart loop into the s-shaped heart loop begins at $49 \mathrm{hr}$ of the development and ends at 69 hour. In the present study, this stage of the development starts at $39-40 \mathrm{hr}$ and finishes at $52-55$ hour.

These previous expected findings are not strange because of the short period of the incubation of the quail embryo (16 to 17 days) unlike that of the chick embryos which lasts 21 days. So, it is expected to find the external changes of the developing quail heart to occur earlier than that of the chick heart.

\section{Mystery about the Bulbus cordis:}

Romanoff (1960) reported that the Sulcus bulboventricularis gradually disappears as the proximal part of the Bulbus cordis is incorporated into the ventricle, while the distal part of the Bulbus cordis becomes the proximal part of the Truncus arteriosus.

Männer (2000) mentioned the dilatation following the Ventriculus primitivus as the Conus arteriosus. He never used the nomenclature of the Bulbus cordis. Moreover, he replaced the nomenclature of Sulcus bulboventricularis with Sulcus conoventricularis. Patten and Carlson, (1974) termed that the part of the ventricle that narrows abruptly to give rise to the Truncus arteriosus as the ventricular cone or Conus arteriosus.

In this study, we cleared that the dilatation following the Ventriculus primitivus is called the Bulbus cordis and gradually incorporates into the ventricle as mentioned by Romanoff (1960). The narrowing part of the ventricle which is formed after the disappearance of the Bulbus cordis and gave rise to the Truncus arteriosus is termed the Conus arteriosus.

Romanoff (1960) said that the process of incorporation of the Bulbus cordis into the ventricle in the chick embryo heart is continued till the end of the seventh day or sometimes during the eighth day of the development. While in the quail embryo, this process of incorporation is finished during the fourth day of the development.

\section{Conclusions}

1- Principally, there are no different morphological changes between the quail embryo heart development and the chick embryo heart development.

2- The cardiac looping process of the developing quail heart occur earlier than that of the developing chick heart.

3- The heart regions of the developing quail heart are formed earlier than that of the developing chick heart.

4- The most critical period of the heart development is the early stages which include the looping of the heart tube, and the differentiation of the heart regions. The heart needs these events to begin to beat even before the internal morphological changes have been established.

5- The results obtained are important for the embryologists using the quail-chick chimera system in the development. Both quail and chick embryos used in this system must be at the comparable not the same ages of the development to avoid the malformations resulted from using the miss ages.

\section{References}

Barry, A. (1948): Cited in Romanoff, (1960).

Beddington,R.S.P. and Robertson,EJ.(1999): Axis development and early asymmetry in mammals. Cell 96: 195-209.

Boerner-Patzelt, D. (1931): Cited in Romanoff, (1960).

Bouman, H. G. A., Broekhuizen, M. L. A., Baasten, A. M. J., Gittenberger-de Groot, A. C. and Wenink, A. C. G. (1995): A spectrum of looping disturbances in stage 34 chicken 
hearts after retinoic acid treatment. Anat. Rec., 243: 101-108.

Bruno, G. (1918): Cited in Romanoff, (1960).

Carlson, B. M. (1988): Patten's foundations of embryology. $5^{\text {th }}$ ed. McGRAW-HILL BOOK company. New York, Toronto. P. 644-662.

Chang, C. (1932): On the relation of the endo cardium to the blood stream in the em bryonic heart with special reference to the endocardial thickenings in the atrioventricular canal and the bulbus cordis. Anat. Rec., 51: 253-265.

Cooke, J. and Isaac, A. (1998): A cascade of gene action controlling heart asymmetry and tor sion in embryonic development. Trends Cardiovasc Med 8: 215-220.

Creuzet, S., Couly, G., Le Douarin, N. M. (2005): Patterning the neural crest derivatives dur ing development of the vertebrate head: in sights from avian studies. J Anat. Nov; 207(5):447-59. Review

Davies, C.L. (1924): The cardiac jelly of the chick embryo. Anat. Rec., 51: 253-265.

Davies, C.L. (1927): Development of the human heart from the first appearance to the stage found in embryos of twenty paired somites. Carnegie Contrib Embryol., 19: 245-284.

De-Haan, R. L. (1965): Morphogenesis of the vertebrate heart. In: Dehaan R.L. Ursprong H., editors. Organogenesis. New York Holt Rinehart \& Winston. P 377-419.

Dupin, E. and Le Douarin, N. M. ( 2003): Ab stract Development of melanocyte pre cursors from the vertebrate neural crest. Oncogene. May 19; 22(20):3016-23.Review. PMID: 12789276.

Etchevers, H. C., Couly, G. and Le Douarin, N. M. (2002):Morphogenesis of the branchial vascular sector. Trends Cardio vasc Med. Oct; 12(7):299-304. Review. PMID: 12458092.

Flynn, M. E., Pikalow, A. S, Kimmelman, R. S. and Searls, R. L. (1991): The mechanism of cervical flexure formation in the chick. Anat Embryol 184:411-420.

Garcia-Pelaez, I. and Arteaga, M. (1993): Experimental study of the development of the truncus arteriosus of the chick embryo heart. Time of appearance. Anat Rec 237:378-384.

Graper, L. (1907): Cited in Romanoff, (1960).

Haller, A. V. (1758): Sur la formation du Coeur. (About the formation of the heart.) Lau ner, (2000) sanne: Bousquet MM. Cited by Män-

Harvey, R. P. (1998): Links in the left/right axial pathway. Cell 94: 273-276.
His,W.(1881): Mittheilungen zur Embryologie der Saugethiere und des Menschen. (Communications on the embryology of mammals and man.) Arch Anat physiol 5: 303-329.

His,W.(1885): Anatomie der menschlicher Embryonen.Teil 111 zur Gschichte der Organe. (Anatomy of human embryos. Part 111 development of organs.) Leipzig: Vogel.

Hochstetter, F. (1906): In Hertwig's Handbuch der vergleichenden und experimentellen Ent wickelungeslehre der Wirbeltiere. Jena, G. Fischer. 3(2):-21-166.

Icardo, J. M. (1996): Developmental biology of the vertebrate heart. J Exp Zool 275: 144-161.

Kirby, B. L and Waldo, K. L. (1995): Neural crest and cardiovascular patterning Circ Res 77:211-215.

Le Douarin, N. M. (2004): The avian embryo as a model to study the development of the neural crest: a long and still ongo ing story. Mech Dev. Sep;121(9):1089102. Review.

Lewis, F. T. and Abbott, M. E. (1915): Reversed torsion of the human heart. Anat $\operatorname{Rec}$ 9:103-105.

Lewis, F. T. and Abbott, M. E. (1916): Re versed torsion of the ventricular bend of the embryonic heart in the explana tion of certain forms of cardiac anoma ly. Bull Int Assoc Med Mus 6: 111.

Long, K. D., Kennedy, G. and Balaban, E. (2001): Transferring an inborn auditory perceptual predisposition with inters pecies brain transplants. PNAS 98: 5862-5867.

Luttun, A. and Carmeliet, P. (2003): De novo vasculogenesis in the heart. Cardi ovascular Research. 58 (2): 378-389.

Malpighi, M. (1672): De ovo incubato. (About incubated egg.) London: Martyn. Cited by Männer, (2000).

Manasek, F. J. and Monroe, R. G. (1972): Early cardiac morphogenesis is independent of function. Dev Boil 27:584-588.

Männer, J. (2000): Cardiac looping in the chick embryo: A morphological review with special reference to terminological and biomechanical aspects of the looping process. Anat. Rec. 259:248-262.

Männer,J., Pérez-Pomares,J.M., Macías,D and Muñoz-Chápuli R. (2001): The Origin, Formation and Developmental Significance of the Epicardium: A Re view Cells Tissues Organs.169:89-103. 
Männer, J., Seidl, W. and Steding, G. (1993): Correlation between the embryonic head flexures and cardiac development. An experimental study in chick embryos. Anat. Embryol. 188:269-285.

Männer, J., Seidl, W. and Steding, G. (1995): For mation of the cervical flexure: an experimental study on the chick embryo. Acta Anat 152:1-10.

Manning, A. and McLachlan, J. C. (1990): Looping of chick embryo hearts in vitro. $J$ Anat 168:257-263.

Markwald, R. R., Trusk, T. and Moreno-Rodriguez R. (1998): Formation septation of the tubular heart: integrating the dynamics of morphology with emerging molecular concepts. In: de la Cruz M. V., Markwald R. R, editors.Living morphogenesis of the heart. Boton: Birkhauser. P 43-84.

Nomina Embryologica Veterinaria (2006): Elec Olson, E. N. and Srivastava, D. (1996): Molecular pathways controlling the heart de velopment. Science 272:671-676.

Pander, H.C. (1817): Beitrage zur Entwickelungsgeschichte des Huhnchens im Eye. (Studies on the development of the chick in the egg.) Wurzburg: Bronner. Cited by Männer, (2000).

Patten, B. M. (1922): The formation of the cardiac loop in the chick. Am. J. Anat., 30:373-397.

Patten, B. M. (1964): Textbook of The Foundation of embryology. Second edition, McGRAWHILL book company, INC. New York, San Francisco, London, Toronto.

Patten, B. M. (1971): Early embryology of the chick. $5^{\text {th }}$ ed. McGRAW-HILL BOOK Company. New York. pp 121-130; 164-168; 214-223.

Patten, B. M., and kramer T.C. (1933): The initiation of contraction in the embryonic chick heart. Am. J. Anat., 53:349-375.

Patten, B. M. and Carlson, B. M. (1974): Foundation of embryology. $3^{\text {rd }}$ ed. McGRAW-HILL BOOK
Company. New York. Pp 187-198; 261-274; 203-316; 535-585.

Phillips, R.E., and Williams, C.S. (1944): Cited in Romanoff, (1960).

Romanoff, A.L. (1960): Textbook of The avian emb ryo, Structural and functional development. First edition, The Macmillon company, New York, Brett-Macmillon L td. pp. 681-742.

Roux, W. (1895): Gesammelte Abhandlungen Entwick lungmechanik der Organismen. (Essays on the mechanics of development of organisms.) 2 ed. Leipzig: Engelmann.

Sainsbury, D. (1992): Poultry health and manage ment. $3^{\text {rd }}$ ed. Blackwell scientific publications. Osney Mead. Oxford.

Schoenwolf, G. C. and Garcia-Martinez, V. (1995): Primitive streak origin and state of commitment of cells of the cardiovascular system in avian and mammalian

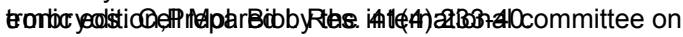

Spitzer, A. (1851): The architecture of normal and malformed hearts. Springfield, IL: Charles C. Thomas.

Stalsberg, H. (1970): Mechanism of dextral looping of the embryonic heart. Am J Cardiol 25:265-271.

Van Praagh, R. (1972): The segmental approach to diagnosis in congenital heart disease. Birth Defects 8: 4-23.

Viragh, S. (1989): Development of the avian and mammalian heart prior to the on set of blood circulation, studied in chick and mouse embryos. Morphol. Igazsagugyi. Orv. SL. Oct; 29(4):255-62.

Waddington, C. H. (1937): The dependence of head curvature on the development of the heart in the chick embryo. J EXP. Biol. 14:229-231.

Wolff, C.F.(1764): Theorie von der Generation. (Theory of development.) Berlin: Birnstiel. Cited by Männer,(2000). 

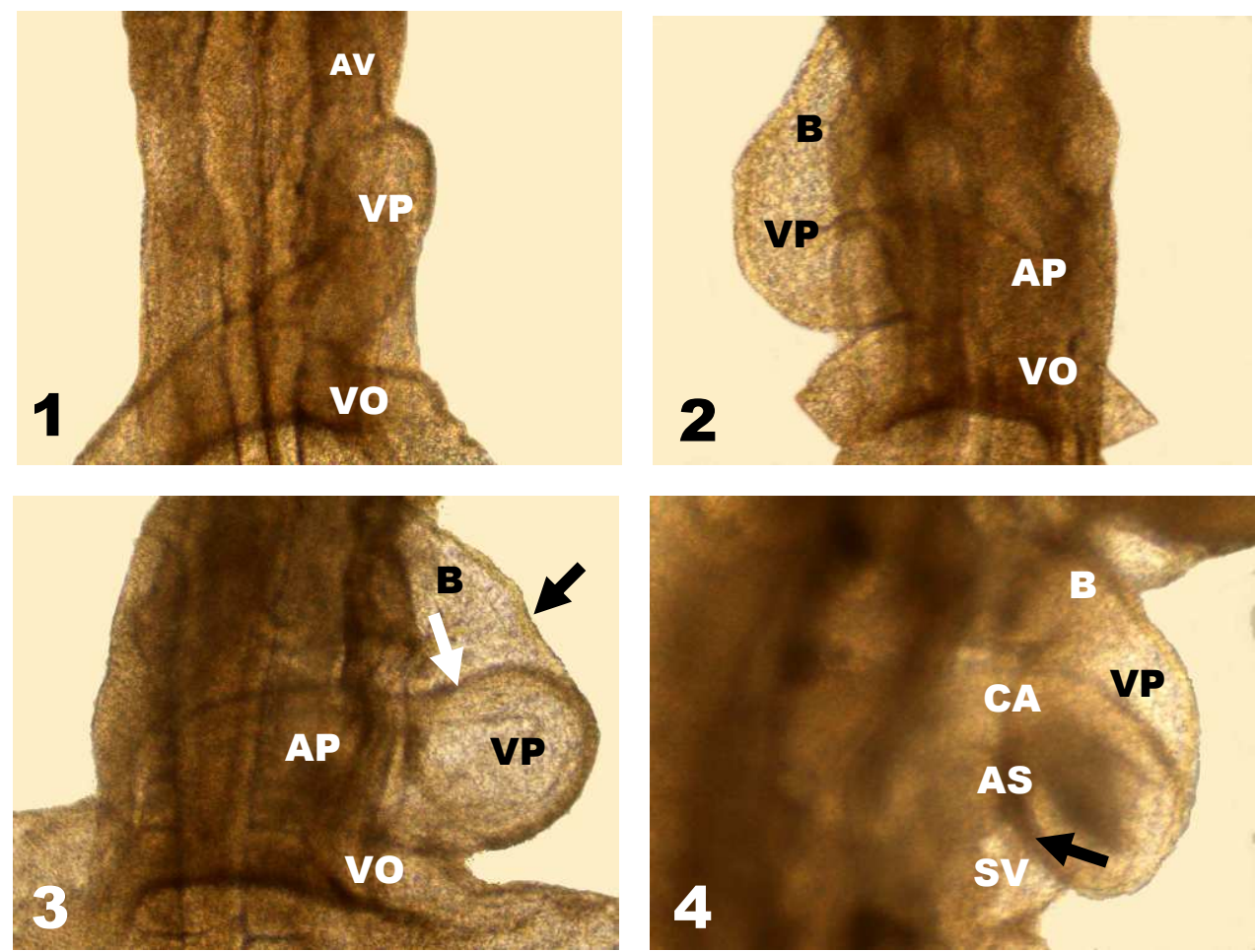

Figure 1: Ventral view of the cardiac region of a quail embryo of about $24-26 \mathrm{hr}$ of incubation photographed under an inverted microscope showing the formed heart tube with only Ventriculus primitivus (VP) region which is connected cranially with the Aorta ventrale (AV) and caudally with the Vena omphalomesenterica (VO) (X 40).

Figure 2: Dorsal view of the cardiac region of a quail embryo of about $28 \mathrm{hr}$ of incubation photographed under an inverted microscope showing bending of the heart tube toward the right side forming u-shaped heart tube. The Bulbus cordis (B) and the Atrium primitivum (AP) are distinguished cranial and caudal to the Ventriculus primitivus (VP) respectively (X 40$)$.

Figure 3: Ventral view of the cardiac region of a quail embryo of about $30 \mathrm{hr}$ of incubation photographed under an inverted microscope showing not only increasing in the craniocaudal length of the heart tube which leads to increasing in the twisting process toward the right, but also increasing in the diameter which lead to illustration of the heart regions which are separated from each other by grooves (indicated by arrows) $(\mathbf{X} 40)$. Black arrow $=$ Sulcus bulboventricularis, White arrow $=$ Sulcus atrioventricularis, $\mathbf{A P}=$ Atrium primitivus, $\mathbf{V P}=$ Ventriculus primitivus, $\mathbf{B}=$ Bulbus cordis, $\mathbf{V O}=$ Vena omphalomesenterica.

Figure 4: Sinstro-dorsal view of the cardiac region of a quail embryo of about $38 \mathrm{hr}$ of incubation photographed under an inverted microscope showing right ward flapping/lateralization of the Ventriculus primitivus (VP) accompanied by addition of the Sinus venosus (SV) to the venous pool which separated from the atrium by Sulcus sinoatrialis (indicated by black arrow) and appearance of a long narrow part called Canalis atrioventricularis (CA) between the atrium and the ventricle $(\mathbf{X} 40)$. 

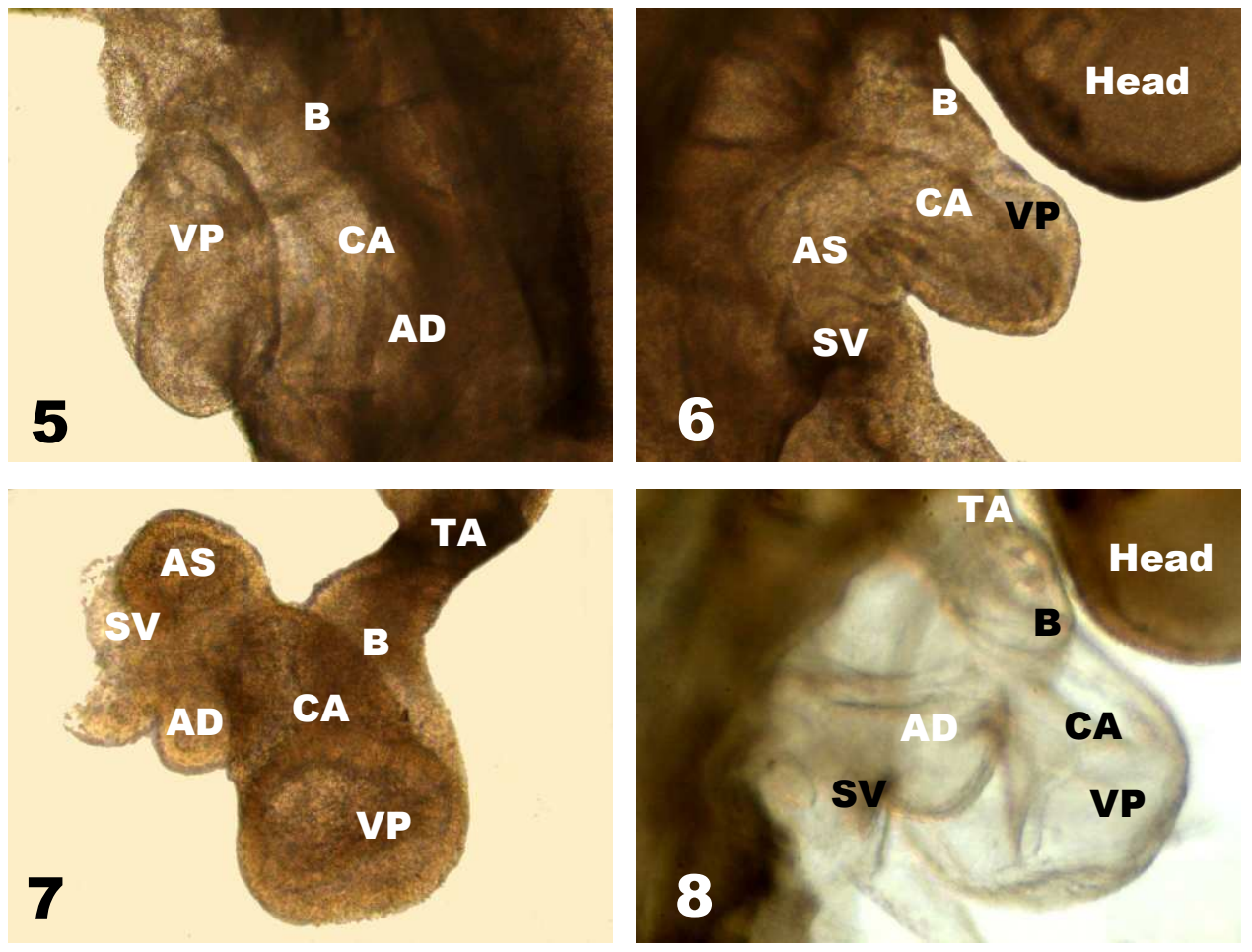

Figure 5: Dextro-dorsal view of the cardiac region of a quail embryo of about $39 \mathrm{hr}$ of incubation photographed under an inverted microscope clearing the right ward flapping process and shortening the distance between the Bulbus (B) and the Canalis atrioventricularis (CA) until become close together to form c-shaped heart loop (X 40).

VP $=$ Ventriculus primitives, $\mathbf{A D}=$ Atrium dexterum

Figure 6: Sinstral view of the cardiac region of a quail embryo of about $48 \mathrm{hr}$ of incubation photographed under an inverted microscope showing transformation of the c-shaped heart loop into s-shaped heart loop and elongation of the Canalis atrioventricularis (CA) $(\mathbf{X}$ 40)

$\mathbf{B}=$ Bulbus cordis, $\mathbf{V P}=$ Ventriculus primitives, $\mathbf{A S}=$ Atrium sinstrum, $\mathbf{S V}=$ Sinus venosus.

Figure 7: Sinstral view of the heart of a quail embryo of about $50 \mathrm{hr}$ of incubation photographed under an inverted microscope showing the movement of the Ventriculus primitivus (VP) over the Atrium primitivum (AD) toward its definitive position. The long part connected to the Bulbus cordis is called Truncus arteriosus (TA) (X 40).

$\mathbf{B}=$ Bulbus cordis, $\mathbf{C A}=$ Canalis atrioventricularis, $\mathbf{V P}=$ Ventriculus primitives, $\mathbf{A S}=$ Atrium sinstrum, $\mathbf{A D}=$ Atrium dexterum, SV = Sinus venosus

Figure 8: Sinisral view of the cardiac region of a quail embryo of about $52 \mathrm{hr}$ of incubation photographed under an inverted microscope showing the shift of the Ventriculus primitivus (VP) from its original position cranial to the atrial region toward its definitive position caudal to it to form s-shaped heart loop. (X 40). TA $=$ Truncus arteriosus, $\mathbf{B}=$ Bulbus cordis, $\mathbf{C A}=$ Canalis atrioventricularis, $\mathbf{V P}=$ Ventriculus primitives, $\mathbf{A D}=$ Atrium dexterum, $\mathbf{S V}=$ Sinus venosus . 

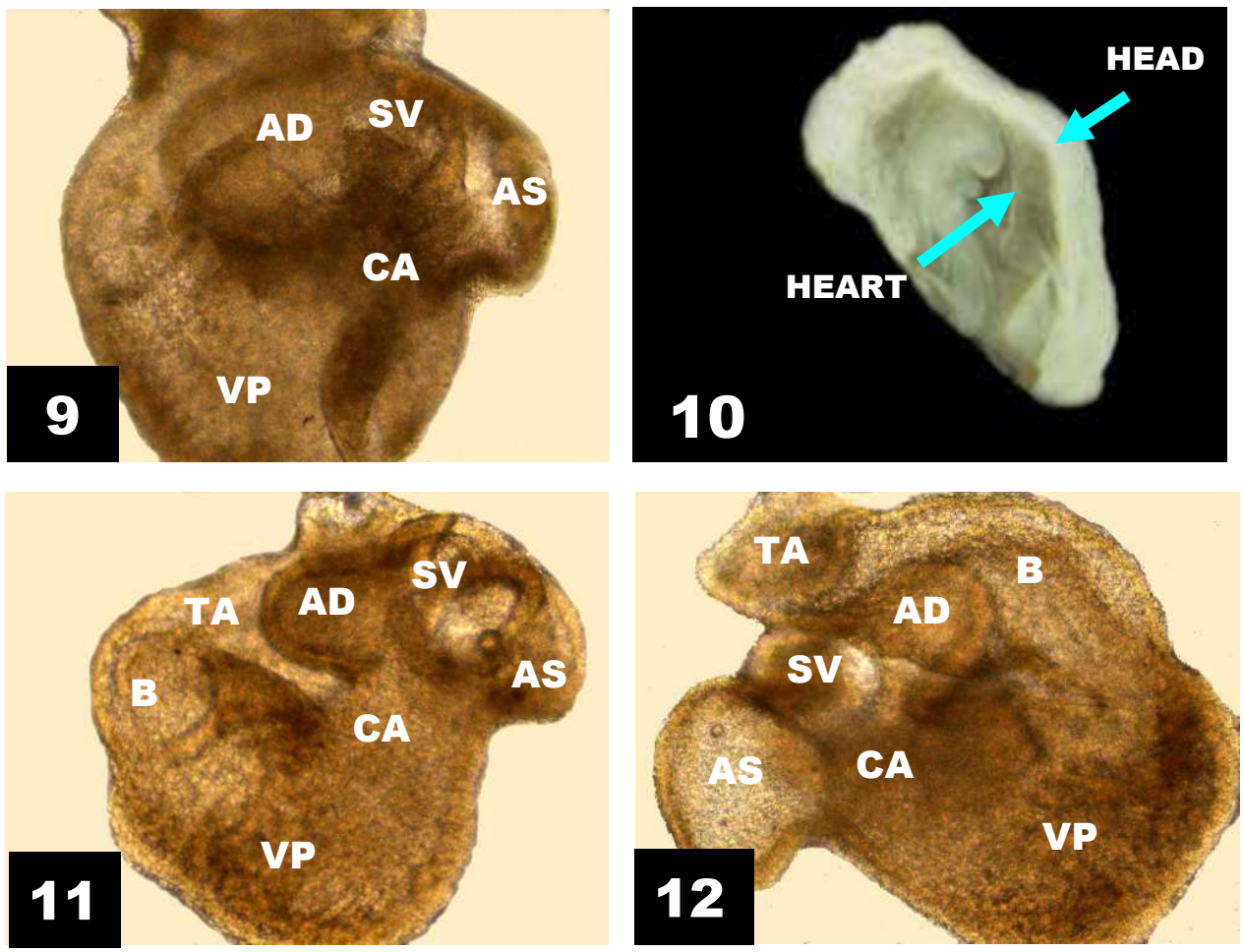

Figure 9: Caudal view of the heart of a quail embryo of about $55 \mathrm{hr}$ of incubation photographed under an inverted microscope showing the shift of the Sinus venosus (SV) from its original position caudal to the atrial region toward its definitive position dorsal to it, and the shortening of the Canalis atrioventricularis (CA) (X 40). VP = Ventriculus primitives, $\mathbf{A D}=$ Atrium dexterum, AS = Atrium sinstrum .

Figure 10: Dextro-caudal view of the heart of a quail embryo of about $63 \mathrm{hr}$ of incubation photographed under an inverted microscope showing the diminishing of the Bulbus (B) size where its proximal part incorporates into the Ventriculus primitivus (VP) and the distal part becomes the proximal part of the Truncus arteriosus (TA), and the appearance of the Sulcus interventricularis (indicated by the white arrow). The internal wall of the Ventriculus primitivus shows the beginning of trabecular formation (indicated by the dark dots in the wall of the ventricular region) (X 40).

Figure 11: Sinistral view of the heart of a quail embryo of about $72 \mathrm{hr}$ of incubation photographed under an inverted microscope showing continuous diminishing of the Bulbus (B) size. The Sinus venosus (SV) become dorsal to the atrium. The Truncus arteriosus (TA) shows internal devision, and the internal wall of the Ventriculus primitivus (VP) shows extensive trabecular formation (indicated by the dark dots in the wall of the ventricular region) $(\mathbf{X} 40)$.the pink arrow refers to the longitudinal groove on the ventrocephalic surface of the atrial region which marks the location of the Septum interatriale.

Figure 12: Sinistral view of the heart of a quail embryo of about $74 \mathrm{hr}$ of incubation photographed under an inverted microscope showing disappearance of the Bulbus. The part that narrows abruptly to give rise to the Truncus arteriosus (TA) is termed the Conus arteriosus (C). The Septum aorticopulmonale is achieved by the proliferation of the two opposing endocardial ridges (ER) of the Truncus arteriosus (TA) (indicated by the black arrows). The Ventriculus primitivus (VP) start to divides into two chambers by the coalescence of the Trabeculae carneae (TC) to form the Septum interventriculare (SIV) which is indicated externally by the Sulcus interventricularis (indicated by the white arrow) $(\mathbf{X}$ 40). $\mathbf{A S}=$ Atrium sinstrum, $\mathbf{C A}=$ Canalis atrioventricularis, VS = Ventriculus sinister. 


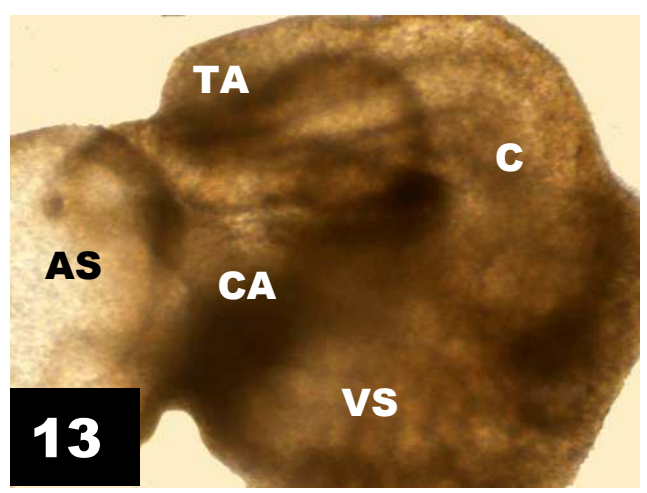

Figure 13: Sinisral view of the heart of a quail embryo of about $76 \mathrm{hr}$ of incubation photographed under an inverted microscope showing the continuous development of the Septum aorticopulmonale (SA) (indicated by the pink arrows), and continuous development of the Septum interventriculare (SIV), so, the Sulcus interventricularis becomes deeper (indicated by the white arrow) (X 40). 